\title{
Occult carcinoma in an adult choledochal cyst
}

\author{
J.F. Dowsett ${ }^{1}$, J. Rode ${ }^{2}$, V.A. Chandiramani ${ }^{3}$ and R.C.G. Russell ${ }^{3}$
}

Departments of ${ }^{1}$ Gastroenterology, ${ }^{2}$ Pathology and ${ }^{3}$ Surgery, University College and Middlesex Hospital Medical School, London, UK

\begin{abstract}
Summary: The complications of choledochal cyst are avoidable if diagnosed early, and adequate resection undertaken. This case report describes the long history of right subcostal pain in a young man of 26 who had a squamous carcinoma in a choledochal cyst diagnosed after serial section of the excised cyst. Subsequent resection of the head of the pancreas showed histological residual tumour from which he died 4 months later. This case illustrates the need for complete early excision of a choledochal cyst to prevent this complication.
\end{abstract}

\section{Introduction}

Focal dilatation of the biliary tree consistent with the modern concept of choledochal cyst was first described by Douglas in 1852, ${ }^{1}$ although Vater may have described a case in the previous century. ${ }^{2}$ The disease remained difficult to define and categorize until the classification of Todani et al. ${ }^{3}$ based on the earlier work of Alons-Lej et al. ${ }^{4}$ The importance of the condition lies in the complications, ${ }^{5,6}$ of which carcinoma is well described. The incidence of carcinoma is $2.4-14 \%, 5,7-11$ but varies considerably with age, being $0.7 \%$ in those less than 10 years of age, $6.8 \%$ between the age of 10 and 20 years and $14.3 \%$ over the age of $20 .^{12}$

This case report is presented in order to draw attention to the diagnostic difficulties of the condition, and the rapid fatality which can occur even after radical treatment.

\section{Case report}

A 26 year old white male presented in July 1988 with a one week history of acute cholangitis, with severe right upper quadrant and posterior scapular pain, jaundice, fever and rigors. The pain was partially relieved by vomiting and he had lost $1-2 \mathrm{~kg}$ in weight. Similar but shorter attacks (1-2 days) of identical but less severe pain had occurred every 2-4 months since the age of 14 but had never previously been associated with fever or jaundice. There was no other personal or family history of note. Examination revealed a temperature of $38.5^{\circ} \mathrm{C}$, marked right upper quadrant tenderness

Correspondence: R.C.G. Russell, M.S., F.R.C.S., The Middlesex Hospital, Mortimer Street, London W1N 8AA, UK.

Accepted: 16 August 1990 with voluntary guarding and mild scleral icterus. The haemoglobin was $14.5 \mathrm{~g} / \mathrm{dl}$, white cell count $7.0 \times 10^{9} / 1$, bilirubin $252 \mu \mathrm{mol} / 1$ (NR: $3-17$ ), alkaline phosphatase 828 IU/1 (NR: 100-280), albumin $42 \mathrm{~g} / 1$ (NR: $35-53$ ), aspartate transaminase 559 IU/1 (NR: 5-40), calcium $2.42 \mathrm{mmol} / \mathrm{l}$ (NR: 2.22.6) and urea $4.8 \mathrm{mmol} / 1$ (NR: 3.0-8.0). Serum amylase was normal. Ultrasound and compute $\$$ tomographic (CT) scan (Figure la) showed cystie dilatation of the common bile and hepatic ducts and the distal left and right hepatic ducts with mildly thickened walls; there was no dilatation of the proximal intrahepatic ducts and the liver echogenicity was normal. The gallbladder was not seen. The cyst appeared to extend deep into the posterior pancreatic substance down to the papilla. There were no filling defects seen within the cyst. A Todani Type la choledochal cyst was diagnosed. The cholangitis settled progressively with intravenous antibiotics but the pain continued constantly with added intermittent severe attacks requiring parenteral narcotics. Preoperative endoscopic retrograde cholangiopancreatography (ERCP) under antibiotic cover confirmed the presence of a choledochal cyst and documented a short intraduodenal common channel $(3 \mathrm{~mm})$ and narrow irregular intrapancreatic bile duct (Figure 1b). The papilla and pancreatic duct were normal. There appeared to be multiple small filling defects within the cyst suggestive of cystolithiasis though cyst filling at ERCP was minimized to prevent cholangitis.

At operation, the cyst and gallbladder were excised and a roux-en-Y hepaticojejunostomy fashioned. Postoperative recovery was complicated briefly by a right basal pneumonia. Histopathological examination of the specimen, however, revealed an area of adenocarcinoma with squamous differentiation at the distal end of the cyst (see 
below). Pancreatoduodenectomy with the excision of the remaining bile duct was therefore undertaken. This was complicated by recurrent right basal pneumonia despite epidural analgesia, and Enterobacter sp. bacteraemia and a transient bile leak. The patient left hospital well after a total of 6 weeks' stay but represented with malignant ascites and severe pain 4 months later and died from carcinomatosis.

(a)

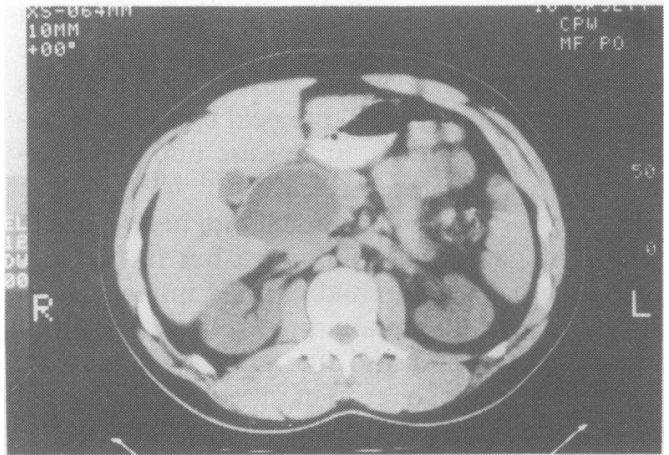

(b)(i)

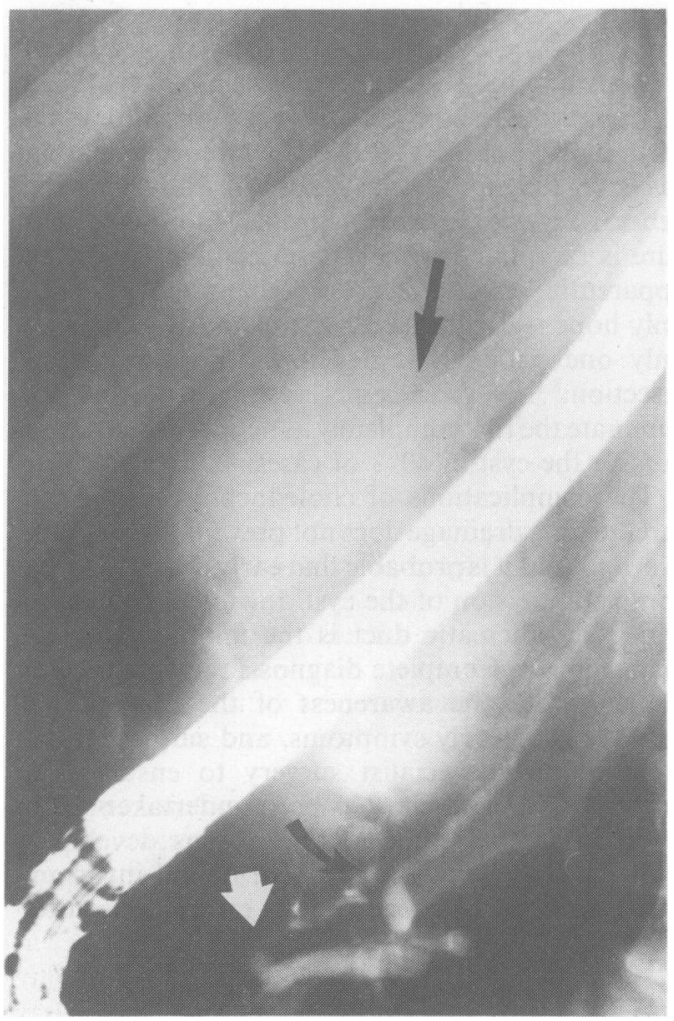

(b)(ii)

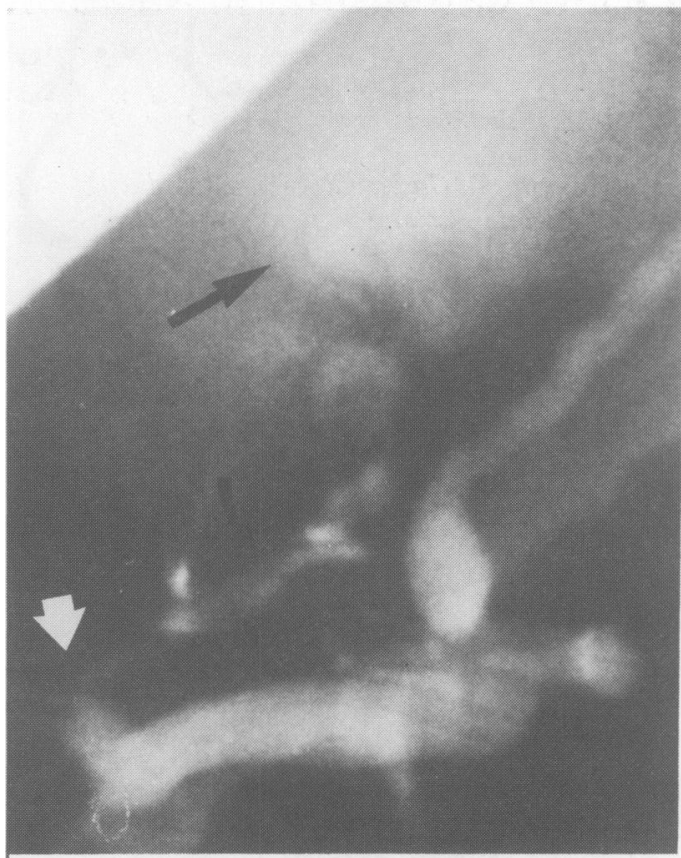

Figure 1 (a) CT scan showing large thin-walled choledochal cyst. (b) ERCP showing the choledochal cyst (straight black arrow), the 2-3 mm common pancreatobiliary channel (white arrow) and the irregular, abnormal low common bile duct (curved black arrow).

\section{Histopathology}

The resected cyst specimen was $9 \times 6 \times 5 \mathrm{~cm}$ and had a $2 \mathrm{~mm}$ thick fibrous wall. It contained bilestained fluid but no stones and had a macroscopically smooth lining. The gallbladder $(9 \times 2 \times 2$ $\mathrm{cm})$ opened via a short straight cystic duct into the proximal cyst and contained no stones. The specimen was extensively sampled, especially within its immediate supra- and retropancreatic portion. One section showed the full thickness of the wall infiltrated by moderate to poorly differentiated adenocarcinoma with some foci of squamous differentiation (Figure 2). The presence of severe epithelial atypia of the choledochal cyst lining adjacent to the infiltrating carcinoma suggested the origin of the tumour from the cyst rather than infiltration in from the adjacent pancreas. Immunocytochemically there was no carcinoembryonic antigen production. Acute and chronic inflammation of the cyst mucosa was present throughout the entire cyst.

The pancreatoduodenectomy specimen showed the changes of recent surgery and an enlarged $1 \mathrm{~cm}$ node between the head of the pancreas and the wall of the duodenum. Microscopically, residual 




Figure 2 Histopathological specimen showing adenocarcinoma with squamous metaplasia (H\&E; magnification $\times 230$ ).

tumour was present within the wall of the operation wound in the posterior pancreatic head. The enlarged lymph node, detected macroscopically, and a further node were involved by metastatic carcinoma. Perineural invasion of a large degenerated nerve was also seen. No carcinoma was seen at the resection margins. The non-directly involved pancreatic head and neck were histologically normal.

Cytological examination of the ascitic fluid at representation 4 months later showed typical adenocarcinoma cells.

\section{Discussion}

Choledochal cyst is uncommon in the United Kingdom..$^{13}$ It is an anomaly which may present at any age with the classical triad of pain, abdominal mass and jaundice, although in the adult, recurrent abdominal pain alone is the commonest presenting feature, ${ }^{5,6,14}$ requiring an awareness of this possibility by the ultrasonographer screening a patient with upper abdominal pain. Presentation in adult- hood is usually associated with the development of complications such as choledocholithiasis, portal hypertension due to secondary biliary cirrhosis and carcinoma.$^{15}$ The presentation with these complications is the rationale for the treatment of a choledochal cyst by excision of the cyst as opposed to simple drainage.

Neoplasm is a well-recognized complication of all forms of choledochal cysts ${ }^{11,16,17}$ and was first reported in Type I cysts by Irwin and Morrison in $1944{ }^{18}$ Type $V$ cysts in $1968^{19}$ and in choledochoceles in 1980. ${ }^{11}$ This complication is most commonly seen in Types I and IV cysts, that is cysts involving the common bile duct. In these patients a distended gallbladder may be a good clinical guide to the presence of a neoplasm. ${ }^{20}$ Adenocarcinoma is by far the commonest histological type, but squamous, adenosquamous, anaplastic and sarcomatous varieties have been described. ${ }^{11,16,18,20}$

The reason for the development of neoplasms in the choledochal cyst is unknown but in this and other such cases acute and chronic inflammation within the cyst is common, probably as a result of stasis with infection and the reflux of pancreatic juice into the cyst as a result of the common channel between the bile duct and the pancreatic duct. ${ }^{21,22}$ The long history in the present case undoubtedly predisposed to the development of the carcinomao and the difficulty in diagnosing the conditiot despite careful preoperative investigatiof emphasizes the care required in the management of this rare anomaly. Further, routine histology failed to detect the lesion, and it was not until serial section of the entire cyst had been undertaken that the true diagnosis was apparent. However, the general experience with neoplasm in cysts is that cure is rare and the short term prognosis of even apparently resected tumours is poor., ${ }^{9}, 10,13,15$ The only hope is early cyst detection and resection ${ }^{7}$ as only one patient has developed neoplasia after resection. ${ }^{8}$ Nevertheless, resection will not eliminate the risk completely as neoplasia may arise outside the cyst in $40 \%$ of cases.

The complications of choledochal cyst are life threatening; drainage does not prevent these complications, but it is probable that early diagnosis with complete excision of the cyst down to its junction with the pancreatic duct is the minimal surgical management. Complete diagnosis requires careful imaging with the awareness of the non-specific nature of the early symptoms, and surgical treatment requires specialist surgery to ensure that prophylactic treatment has been undertaken for it is probable that once carcinoma has developed with its early lymphatic and perineural invasion, cure is unlikely by even the most radical clearance. 


\section{References}

1. Douglas, A.H. Case of dilatation of the common bile duct. Monthly J Med Sci 1852, 14: 97-100.

2. Nagata, E., Sakai, K., Kinoshita, H. \& Hirohashi, K. Choledochal cyst - complications of anomalous connection between the choledochus and pancreatic duct and carcinoma of the biliary tract. World $J$ Surg 1986, 10: 102-110.

3. Todani, T., Watanabe, Y., Narusue, M., Tabuchi, K. \& Okajima, K. Congenital bile duct cysts - classification, operative procedures and review of 37 cases including cancer arising from choledochal cyst. Am J Surg 1977, 134: 263-269.

4. Alons-Lej, F., Rever, W.B. \& Pessagno, D.J. Congenital choledochal cyst with a report of two cases and analysis of 94 cases. Int Abstr Surg 1959, 108: 1-30.

5. Flanigan, D.P. Biliary cysts. Ann Surg 1975, 182: 635-643.

6. Nagorney, D.M., McIlraith, D.C. \& Adson, M.A. Choledochal cyst in adults - clinical management. Surgery 1984, 96: 656-661.

7. Rattner, D.W., Schapiro, R.H. \& Warshaw, A.L. Abnormalities of the pancreatic and biliary ducts in adult patients with choledochal cysts. Arch Surg 1983, 118: 1068-1073.

8. Powell, C.S., Sawyers, J.L. \& Reynolds, V.H. Management of adult choledochal cysts. Ann Surg 1981, 193: 666-676.

9. Etienne, J.C., Bouillot, J.L. \& Alexandre, J.H. Cholangiocarcinome develope sur maladie de Caroli - a propos d'un cas. Revue de la literature. J Chir 1987, 124: 161-164.

10. Rossi, R., Silverman, M.L., Braasch, J.W., Munson, J.L. \& ReMine, S.G. Carcinomas arising in cystic conditions of the bile ducts - a clinical and pathological study. Ann Surg 1987, 205: 377-384.

11. Todani, T., Tabuchi, K., Watanabe, Y. \& Kobayashi, T. Carcinoma arising in the wall of congenital bile duct cysts. Cancer 1979, 44: 1134-1141.
12. Voyles, C.R., Smadja, C., Shands, C. \& Blumgart, L.H. Carcinoma in choledochal cysts - age related incidence. Arch Surg 1983, 118: 986-988.

13. Robertson, J.F.R. \& Raine, P.A.M. Choledochal cyst - a 33 year review. Br J Surg 1988, 75: 799-801.

14. Crittenden, S.L., McKinley, M.J. Choledochal cyst - clinical features and classification. Am J Gastroenterol 1985, 80: 643-647.

15. Yoshida, H., Itai, Y., Minami, M., Kokubo, T., Ohtomo, K. \& Kuroda, A. Biliary malignancies occurring in choledochal cysts. Radiology 1989, 173: 389-392.

16. Dayton, M.T., Longmire, W.P. \& Tompkins, R.K. Caroli's disease - a premalignant condition? Am J Surg 1983, 145: 41-48.

17. Ozawa, K., Yamada, T., Matumoto, Y. \& Tobe, R. Carcinoma arising in a choledochocele. Cancer 1980, 45: 195-197.

18. Irwin, S.T. \& Morrison, J.E. Congenital cyst of the common bile duct containing stones and undergoing cancerous change. Br J Surg 1944, 32: 319-321.

19. Schiewe, R., Bandisch, E. \& Erhardt, G. Angeborene intrahepatische gallengangzyste mit steinbildung und maligner entartung. Bruns Beitr Klin Chir 1968, 216: 264-271.

20. Tsuchiya, R., Harada, N., Ito, T. et al. Malignant tumours in choledochal cysts. Ann Surg 1977, 186: 22-28.

21. Yamauchi, S., Koga, A., Matsumoto, S., Tanaka, M. \& Nakayama, F. Anomalous junction of pancreatobiliary duct without congenital choledochal cyst - a possible risk for gallbladder cancer. Am J Gastroenterol 1987, 82: 20-24.

22. Kimura, K., Ohto, M., Saisho, H. et al. Association of gallbladder carcinoma and anomalous pancreatobiliary duct union. Gastroenterology 1985, 89: 1258-1265. 